studies. The author lists other diseases with MR lesions in the globus pallidus including Leigh syndrome, Hallervorden-Spatz disease, hemolytic uremic syndrome (associated with E coli 0157:H7 and Shigella dysenteriae food poisoning), carbon monoxide intoxication, hepatic encephalopathy, and neurofibromatosis. See Progress in Pediatric Neurology II (PNB Publishers, 1994, pp242-3) for a previous article by the same author and commentary on MRI in 22 athetotic cerebral palsied children. The value of the MRI in the timing of basal ganglia pathology has been alluded to in other reports of dyskinetic and dystonic cerebral palsy (ibidem. pp243-4). Of 219 dyskinetic CP cases seen between 1955 and 1986 in the Cheyne CP Centre, Chelsea, London, $25 \%$ had been diagnosed with kernicterus.

\title{
VITAMIN A SUPPLEMENTS AND BULGING FONTANELLE
}

Safety of vitamin A supplements in early infancy was investigated by double-blind, randomized, placebo-controlled trial in 167 infants in the Urban Surveillance System area of the International Centre for Diarrhoeal Research, Bangladesh. Three doses of 25000 IU of vitamin A or placebo were given at 6,12 and 17 weeks of age, and infants were examined by physicians on days 1, 2, 3 and 8 after supplementation. Bulging fontanelle occurred in $9(10.5 \%)$ infants receiving vitamin $A$ compared to $2(2.5 \%)$ in the placebo group $(\mathrm{p}<0.05)$. The side effect was not observed after the first dose, 3 infants were affected after the second supplement, and 9 after the third. A cumulative effect of vitamin A was likely. (Baqui $\mathrm{AH}$ et al. Bulging fontanelle after supplementation with $25000 \mathrm{IU}$ of vitamin A in infancy using immunization contacts. Acta Paediatr August 1995;84:863-6). (Respond: Dr AH Baqui, Urban MCH-FP Extension Project, ICDDR,B, GPO Box 128, Dhaka 1000, Bangladesh).

COMMENT. The infants in this study received vitamin A supplements together with the routine DPT/OPV immunization. Bulging of the fontanelle has been reported in the US as a side effect of immunization with DTP vaccine and DT vaccine. (Gross TP et al. I Pediatr 1989;114:423-5 [cited in above study]). An additive or synergistic effect of the immunization cannot be excluded. The reliability of the clinical assessment of the fontanelle by observation and palpation is also debated, and a probable underestimation of vitamin A toxicity is suggested by the authors.

With present day enthusiasm for supplemental vitamins and a common attitude of nonchalance toward possible vitamin overdosage, the recognition of early symptoms and signs of vitamin toxicity is important. (Millichap JG. Environmental Poisons in Our Food, Chicago, PNB Publishers, 1993).

\section{HEADACHE DISORDERS}

\section{BRAIN IMAGING INDICATIONS FOR HEADACHES}

Charts of all children referred to the pediatric neurology clinic, Schneider Children's Hospital, New Hyde Park, NY, for evaluation of headaches over a 2-year period were reviewed retrospectively for headache characteristics, indications for performing CT and MRI studies, and imaging results. Of 133 patients ages 3 to 18 years, $52 \%$ had migrainous headaches, $21 \%$ chronic tension headaches, and $19 \%$ were unclassified. The indications for 